\title{
To Grow or to Age: New Research in Growth Hormone Juan Ding*
}

Schepens Eye Research Institute, Massachusettes Eye and Ear Institute, Department of Ophthalmology, Harvard Medical School, 20 Staniford St, Boston, MA 02114, USA

Growth hormone $(\mathrm{GH})$ is a pituitary hormone that was first isolated in 1944 [1]. In the 1960s the pituitary GH extracted from cadavers was used in GH-deficient children, and in 1985 the recombinant human $\mathrm{GH}$ (rhGH) was approved for clinical use by the United States Food and Drug Administration [2]. Despite a long history of research, a lot remains unclear about the actions of $\mathrm{GH}$, and many of its new roles are emerging, making this hormone an attractive subject of research.

$\mathrm{GH}$ is a hormone with diverse actions. As the name implies, $\mathrm{GH}$ plays a critical role in body growth. At the onset of puberty, GH reaches its peak level, leading to the elongation of the long bones and rapid linear growth. GH induces the expression of insulinlike growth factor-1 (IGF-1) in the liver, which mediates part of the growth-promoting action of GH. GH and IGF-1 both decline rapidly from early teens and decline thereafter as a function of age. Another well-known action of GH is the anabolic effect in the skeletal muscle, resulting in enhanced protein synthesis and increased muscle mass. In contrast, GH induces a catabolic effect in the adipose tissue, resulting in fat loss [3]. Because of these effects in the muscle and fat, GH is often abused and mis-used by athletes. In addition to these classical actions of GH, other documented although less-well studied effects of $\mathrm{GH}$ include fluid retention, reproduction and immunity. GH acts on the renin-angiotensin-aldosterone system to promote fluid retention [4]. In this regard, both extracellular volume and plasma volume are decreased in $\mathrm{GH}$ deficient patients and normalized after $\mathrm{GH}$ replacement therapy [4]. GH also regulates reproduction. Normal GH signaling is needed for folliculogenesis, ovarian maturation, ovulation, and pregnancy in females and for spermatogenesis and the Leydig cell function in males [5]. Adding to its diverse physiological effects, GH also plays an important role in immune modulation. It stimulates $\mathrm{T}$ and $\mathrm{B}$ cells proliferation and immunoglobulin synthesis, promoting the differentiation of myeloid progenitor cells and modulates cytokine response [6]. These physiological effects of GH warrant further study to understand the related health issues and potential applications in therapeutics.

In recent years, $\mathrm{GH}$ has been shown to regulate aging. Animal studies have demonstrated that disrupted GH signaling results in increased longevity [7], whereas increased GH signaling leads to premature aging $[8,9]$. Thus GH shows a pleiotropic effect- beneficial at early age for fitness and reproduction while detrimental at old age [10]. The mechanism for the aging promoting effect is not completely understood, but may involve increased insulin resistance and cancer incidence, and reduced stress defense and mitochondria functions associated with prolonged increase of GH signaling [10]. In humans, acromegaly, a disorder of excess GH secretion, is known to be associated with hypertension, cardiovascular anomaly, diabetes, respiratory problems and increased mortality if untreated [11], which is consistent with studies of GH transgenic mice. However, increased lifespan has not been observed in Laron Syndrome subjects, who have mutations in their $\mathrm{GH}$ receptor (GHR) gene therefore no $\mathrm{GH}$ signaling. This is in contrast to GHR null mice which show a $50 \%$ increase in lifespan compared to control mice. Interestingly though, Laron subjects have a decreased incidence of cancer and diabetes [12], thus supporting the notion that disrupted GH signaling in humans reduces the age-related diseases such as cancer and diabetes.

Concerning the role of $\mathrm{GH}$ in aging, several questions remain outstanding. First of all, we still do not know if reducing GH signaling will increase longevity in humans. Despite clear evidence in mice, it has not been proven that human Laron syndrome subjects have increased lifespan. Although complete abolishment of GH signaling increases lifespan in mice, attenuated GH signaling as seen in mice over expressing a GH antagonist does not prolong lifespan [7], neither does GH deficiency in human adults - if anything, GH deficiency in humans causes central obesity, metabolic syndrome, reduced bone mineral density, reduced muscle mass and strength, fatigue and reduced quality of life and warrants GH replacement therapy [13]. So it appears that the aging benefit is only present when GH signaling is completely lost but not partially reduced. What is the mechanism of this phenomenon?

On the other hand, a somewhat rampant view holds that since GH declines as we age, GH replacement may restore youthfulness and delay aging, hence debate persists on whether or not GH treatment in the elderly will improve their quality of life and make them look and feel younger. So far there is no solid evidence to support the notion that GH is anti-aging, but this does not seem to dampen the enthusiasm for this hormone symbolic of growth and therefore youth. What significance will the dose, timing and duration of GH signaling have that may affect aging? It is widely accepted that too much GH is bad, but how about instead of dosing up like an illicit athlete, we simply restore the $\mathrm{GH}$ levels of a 70-year-old to those of a 30-year-old? And does it matter whether $\mathrm{GH}$ is given to people at 70 or 40 ? Also, the age-promoting effect is seen in chronic excess of GH, which means the entire lifespan in a short-lived GH transgenic mouse, and many years in an acromegalic human, but it is not clear if short-term use of GH leads to long-term detrimental issues. Clearly safety data should be collected before people jump into the 'fountain of youth' infused with GH.

Lastly, does GH affect aging differently in males and females? It is known that GH is secreted in different patterns in males and females [14], and regulates liver genes and plasma proteins in a sex-dimorphic manner $[15,16]$. It remains to be determined whether $\mathrm{GH}$ affects aging in a sex-dependent manner. The study of these issues and the underlying mechanisms may enable an anti-aging regime involving manipulations of relevant GH signaling components specific to each sex.

*Corresponding author: Juan Ding, Ph.D, Schepens Eye Research Institute Massachusettes Eye and Ear Institute, Department of Ophthalmology, Harvard Medical School, 20 Staniford St, Boston, MA 02114, USA, Tel: 617-912-0288; E-mail: Juan.ding@schepens.harvard.edu

Received March 17, 2012; Accepted March 19, 2012; Published March 21, 2012 Citation: Ding J (2012) To Grow or to Age: New Research in Growth Hormone. J Steroids Hormon Sci 3:e107. doi:10.4172/2157-7536.1000e107

Copyright: (c) 2012 Ding J. This is an open-access article distributed under the terms of the Creative Commons Attribution License, which permits unrestricted use, distribution, and reproduction in any medium, provided the original author and source are credited. 
In summary, $\mathrm{GH}$ is a hormone that has diverse actions. Several of the physiological activities of GH deserve further studies. With much interest in its relatively recent role in aging, GH promises to be an attractive target for future research on the mechanism of aging and therapeutics against aging and age-related diseases.

\section{References}

1. Li CH, Evans HM (1944) The Isolation of Pituitary Growth Hormone. Science 99: 183-184.

2. Kopchick JJ (2003) History and future of growth hormone research. Horm Res 60: $103-112$

3. Møller N, Jørgensen JO (2009) Effects of growth hormone on glucose, lipid, and protein metabolism in human subjects. Endocr Rev 30: 152-177.

4. Møller J, Nielsen S, Hansen TK (1999) Growth hormone and fluid retention. Horm Res 51: 116-120.

5. Chandrashekar V, Zaczek D, Bartke A (2004) The consequences of altered somatotropic system on reproduction. Biol Reprod 71: 17-27.

6. Meazza C, Pagani S, Travaglino P, Bozzola M (2004) Effect of growth hormone $(\mathrm{GH})$ on the immune system. Pediatr Endocrinol Rev 3: 490-495.

7. Coschigano KT, Holland AN, Riders ME, List EO, Flyvbjerg A, et al. (2003) Deletion, But Not Antagonism, of the Mouse Growth Hormone Receptor Results in Severely Decreased Body Weights, Insulin, and Insulin-Like Growth Factor I Levels and Increased Life Span. Endocrinology 144: 3799-3810.
8. Steger RW, Bartke A, Cecim M (1993) Premature ageing in transgenic mice expressing different growth hormone genes. J Reprod Fertil Suppl 46: 61-75.

9. Wolf E, Kahnt E, Ehrlein J, Hermanns W, Brem G, et al. (1993) Effects of long-term elevated serum levels of growth hormone on life expectancy of mice: lessons from transgenic animal models. Mech Ageing Dev 68: 71-87.

10. Bartke A (2011) Pleiotropic effects of growth hormone signaling in aging Trends Endocrinol Metab 22: 437-442.

11. Chanson P, Salenave S (2008) Acromegaly. Orphanet J Rare Dis 3: 17

12. Guevara-Aguirre J, Balasubramanian $P$, Guevara-Aguirre M, Wei M, Madia F, et al. (2011) Growth hormone receptor deficiency is associated with a major reduction in pro-aging signaling, cancer, and diabetes in humans. Sci Trans Med 3: 70.

13. Prodam F, Pagano L, Corneli G, Golisano G, Belcastro S, et al. (2008) Update on epidemiology, etiology, and diagnosis of adult growth hormone deficiency. $J$ Endocrinol Invest 31: 6-11.

14. MacLeod JN, Pampori NA, Shapiro BH (1991) Sex differences in the ultradian pattern of plasma growth hormone concentrations in mice. J Endocrinol 131 395-399.

15. Waxman DJ, O'Connor C (2006) Growth Hormone Regulation of SexDependent Liver Gene Expression. Mol Endocrinol 20: 2613-2629.

16. Ding J, Berryman DE, Jara A, Kopchick JJ (2011) Age- and Sex-Associated Plasma Proteomic Changes in Growth Hormone Receptor Gene-Disrupted Mice. J Gerontol A Biol Sci Med Sci. 